\title{
NATIONAL CONFERENCE ON THE USE OF ON-LINE COMPUTERS IN PSYCHOLOGY
}

\section{EDITORIAL}

This issue of Behavior Research Methods \& Instrumentation is dedicated to the Fifth National Conference on the Use of On-Line Computers in Psychology held at the University of Colorado, Boulder, Colorado on November 5, 1975. The Conference was hosted by the Department of Psychology, University of Colorado. Daniel E. Bailey and Peter G. Polson were responsible for the program and arrangements.

The 1-day Conference was composed of 13 sessions. The two morning sessions consisted of major addresses by C. Leventhal, S. Papert, and J. B. Sidowski. The afternoon and evening sessions were dedicated to symposia, contributed papers, and two user's group meetings (Digital Equipment Corporation and Data General Corporation computers). All presentations are noted in this issue except two: "Design of an experimental control language" by Lee W. Gregg, Carnegie-Mellon University, and "A computer-based system for preparing auditory stimuli" by C. B. Gillman, D. Wilson, J. Hirsch, and P. Morse, University of Wisconsin-Madison.

The proceedings of the first four Conferences are printed in the March 1972, 1973, 1974, and 1975 issues of this Journal, respectively. Copies may be obtained by writing to the Publications Office, The Psychonomic Society, Inc., 1108 West 34 th Street, Austin, Texas 78705 . The cost is $\$ 4.50$ per copy.

The Sixth National Conference on the Use of On-Line Computers in Psychology will meet on the campus of Saint Louis University, Saint Louis, Missouri. The date of the Conference is Wednesday, November 10, 1976. A call for papers, symposia, etc., will be issued shortly.

Membership in the group and participation in the meetings is not limited to psychologists. Information concerning membership and the 1976 Conference may be obtained by writing to the Secretary.Treasurer of the organization, Richard B. Millward, Department of Psychology, Brown University, Providence, Rhode Island 82912. 